\title{
Construction, internal validation and implementation in a mobile application of a scoring system to predict nonadherence to proton pump inhibitors.
}

\author{
Emma Mares-García ${ }^{1}$ ， Antonio Palazón-Bru ${ }^{\text {Corresp.., }}{ }^{1}$ ， David M Folgado-de la Rosa ${ }^{1}$, Avelino Pereira-Expósito ${ }^{2}$, \\ Álvaro Martínez-Martín ${ }^{1}$, Ernesto Cortés-Castell ${ }^{3}$, Vicente F Gil-Guillén ${ }^{1,2}$ \\ 1 Department of Clinical Medicine, Miguel Hernández University, San Juan de Alicante, Alicante, Spain \\ 2 Research Unit, General University Hospital of Elda, Elda, Alicante, Spain \\ 3 Department of Pharmacology, Pediatrics and Organic Chemistry, Miguel Hernández University, San Juan de Alicante, Alicante, Spain \\ Corresponding Author: Antonio Palazón-Bru \\ Email address: antonio.pb23@gmail.com
}

Background. Other studies have assessed nonadherence to proton pump inhibitors (PPIs), but none has developed a screening test for its detection. Objectives. To construct and internally validate a predictive model for nonadherence to PPIs. Methods. This prospective observational study with a one-month follow-up was carried out in 2013 in Spain, and included 302 patients with a prescription for PPIs. The primary variable was nonadherence to PPIs (pill count). Secondary variables were gender, age, antidepressants, type of PPI, non-guideline-recommended prescription (NGRP) of PPIs, and total number of drugs. With the secondary variables, a binary logistic regression model to predict nonadherence was constructed and adapted to a points system. The ROC curve, with its area (AUC), was calculated and the optimal cut-off point was established. The points system was internally validated through 1000 bootstrap samples and implemented in a mobile application (Android). Results. The points system had three prognostic variables: total number of drugs, NGRP of PPIs, and antidepressants. The AUC was $0.87(95 \% \mathrm{Cl}$ : $0.83-0.91, \mathrm{p}<0.001)$. The test yielded a sensitivity of $0.80(95 \% \mathrm{Cl}: 0.70-0.87)$ and a specificity of $0.82(95 \% \mathrm{Cl}: 0.76-0.87)$. The three parameters were very similar in the bootstrap validation. Conclusions. A points system to predict nonadherence to PPIs has been constructed, internally validated and implemented in a mobile application. Provided similar results are obtained in external validation studies, we will have a screening tool to detect nonadherence to PPIs. 


\section{AUTHOR COVER PAGE:}

2 Title: Construction, internal validation and implementation in a mobile application of a scoring 3 system to predict nonadherence to proton pump inhibitors.

4 Authors: Emma Mares-García ${ }^{1}$, Antonio Palazón-Bru ${ }^{1}$, David Manuel Folgado-de la Rosa ${ }^{1}$,

5 Avelino Pereira-Expósito ${ }^{2}$, Álvaro Martínez-Martín' ${ }^{1}$, Ernesto Cortés-Castell $^{3}$, Vicente Francisco

6 Gil-Guillén ${ }^{1,2}$.

7 Institutions:

8 1. Department of Clinical Medicine, Miguel Hernández University, San Juan de Alicante,

9 Alicante, Spain.

10 2. Research Unit, General University Hospital of Elda, Elda, Alicante, Spain.

11 3. Department of Pharmacology, Pediatrics and Organic Chemistry, Miguel Hernández

12 University, San Juan de Alicante, Alicante, Spain.

13 Corresponding author: Prof. Antonio Palazón-Bru, PhD. Department of Clinical Medicine,

14 Miguel Hernández University, Carretera de Valencia - Alicante S/N, 03550, San Juan de

15 Alicante, Alicante (Spain). Phone number: +34 965919449. Fax number: +34 965919450. E-

16 mail: antonio.pb23@gmail.com 
ABSTRACT

Background. Other studies have assessed nonadherence to proton pump inhibitors (PPIs), but none has developed a screening test for its detection.

Objectives. To construct and internally validate a predictive model for nonadherence to PPIs.

Methods. This prospective observational study with a one-month follow-up was carried out in 2013 in Spain, and included 302 patients with a prescription for PPIs. The primary variable was nonadherence to PPIs (pill count). Secondary variables were gender, age, antidepressants, type of PPI, non-guideline-recommended prescription (NGRP) of PPIs, and total number of drugs. With the secondary variables, a binary logistic regression model to predict nonadherence was constructed and adapted to a points system. The ROC curve, with its area (AUC), was calculated and the optimal cut-off point was established. The points system was internally validated through 1000 bootstrap samples and implemented in a mobile application (Android).

Results. The points system had three prognostic variables: total number of drugs, NGRP of PPIs, and antidepressants. The AUC was 0.87 (95\% CI: 0.83-0.91, p<0.001). The test yielded a sensitivity of 0.80 (95\% CI: $0.70-0.87)$ and a specificity of 0.82 (95\% CI: $0.76-0.87)$. The three parameters were very similar in the bootstrap validation.

Conclusions. A points system to predict nonadherence to PPIs has been constructed, internally validated and implemented in a mobile application. Provided similar results are obtained in external validation studies, we will have a screening tool to detect nonadherence to PPIs. 
37

38

39

40

41

42

\section{INTRODUCTION}

Proton pump inhibitors (PPIs) are prescribed in clinical practice for the treatment of gastroesophageal reflux disease, as well as other acid-related disorders (Robinson \& Horn, 2003). The indications for their use are increasing, especially in patients with digestive problems, or those who are taking a medication that may cause damage or secondary diseases such as gastritis, digestive ulcers or bleeding (Domingues \& Moraes-Filho, 2014).

Approximately $20-42 \%$ of patients may not respond correctly to PPI therapy, which can cause gastrointestinal complications in patients using anti-inflammatory drugs (NSAIDs) (van Soest et al., 2007). One of the main factors associated with the lack of effectiveness of PPIs is therapeutic nonadherence, the prevalence of which can reach up to $50 \%$ (Domingues \& MoraesFilho, 2014; Henriksson, From \& Stratelis, 2014). It has also been shown that patients have lower adherence to PPI therapy when there are certain sociodemographic factors, symptoms of gastrointestinal complications, lack of understanding about taking medication or reason for prescription, adverse effects, and an inadequate doctor-patient relationship (Sturkenboom et al., 2003; Fass et al., 2005; Hungin, Rubin \& O'Flanagan, 1999; Dal-Paz et al., 2012; Lanas et al., 2012).

To detect patient nonadherence to PPI therapy, we used the percentage of days covered by the PPI (Domingues \& Moraes-Filho, 2014; Henriksson, From \& Stratelis, 2014), the pill count (Lanas et al., 2012) or the Morisky test (Dal-Paz et al., 2012; Domingues \& Moraes-Filho, 2014). The first two methods are considered direct, as they are objective and allow accurate determination of whether the patient is nonadherent, but are difficult to apply in clinical practice.

On the other hand, the Morisky test (indirect method) is not as accurate as the methods mentioned above and there must be a good doctor-patient relationship (Perseguer-Torregrosa et 
60 al., 2014). In other words, we do not have an objective measure that is easy to apply in clinical

61 practice and that gives us accurate results, i.e., a screening test to determine nonadherence to PPI

62 therapy. For this reason we decided to conduct a prospective study, constructing and internally

63 validating through bootstrapping a predictive model of nonadherence to PPI therapy using

64 objective, easy to measure factors. To facilitate its implementation in routine clinical practice,

65 this model was adapted to a points system and implemented in an application for the Android

66 mobile phone operating system. Provided our points system is validated in other regions, we will

67 have a screening tool to reduce nonadherence to PPI therapy and thus reduce possible

68 gastrointestinal complications (Hedberg et al., 2013; Jonasson et al., 2013; Domingues \&

69 Moraes-Filho, 2014).

MATERIALS \& METHODS

\section{Study population}

73 The study population comprised patients prescribed PPIs (omeprazole, lansoprazole,

74 pantoprazole, rabeprazole and esomeprazole) for any cause in the towns of Elda, Santa Pola and

75 San Vicente del Raspeig, located in the province of Alicante (Spain). This province is situated in 76 the southeast of Spain and in 2013 had a population of 1,854,244 inhabitants. The number of

77 inhabitants of the towns included in the study in 2013 was: 1) Elda, 54,056; 2) Santa Pola,

78 34,134; and 3) San Vicente del Raspeig, 55,781. The health system is free and universal. All

79 medication prescribed by both primary and specialized care physicians is collected by the patient

80 at the pharmacy, where all information is recorded automatically (electronic prescription).

81 Study design and participants 
82 This was a prospective observational one-month follow-up study carried out between August and

83 October 2013, at three pharmacies in the province of Alicante (Elda, Santa Pola and San Vicente

84 del Raspeig). All patients who visited these pharmacies during the study period to collect their

85 prescribed PPIs were invited to participate. The PPI was prescribed by the physician for gastric

86 protection due to use of NSAIDs, gastric problems, or possible interactions between different

87 drugs. Since the objective of our study was to determine which patients did not adhere to PPI

88 medication (prediction of this event), we excluded those who presented problems that prevented

89 them from approaching the pharmacy on subsequent visits to determine whether they were

90 taking the PPI medication correctly.

91 During the month of follow-up, the patients made three visits to the pharmacy (Fig. 1). To

92 prevent the patient withdrawing tablets from the package to achieve good pill counts, as a pretext

93 he or she was instructed to bring all packages so that quality control could be performed on the

94 medication. This procedure was done outside of the patient's vision and only the PPI tablet count

95 was performed. Thus information bias in the primary variable of this study, nonadherence to

96 PPIs, was minimized.

97 A one-month period was chosen, even though PPIs can be prescribed for a longer period,

98 because it was the length of time during which all tablets in the package prescribed should have

99 been taken. Moreover, we must bear in mind that this study was conducted in pharmacies, in

100 order to help prescribing physicians reduce patient treatment nonadherence. This is a

101 consequence of the fact that pharmacy professionals can act on the process and outcomes of

102 healthcare to try to improve adherence to treatment (Foro de Atención Farmacéutica, 2008).

103 Variables and measurements 
104 The primary study variable was therapeutic nonadherence to PPIs by the patient. To determine 105 this variable, the ratio between the total number of tablets taken by the patient at follow-up and

106 the total number of tablets prescribed by the doctor (obtained from the electronic prescription at

107 the first visit) were calculated. We defined nonadherence as when the patient failed to take

108 between $80 \%$ and $110 \%$ of the tablets prescribed by their physician (Perseguer-Torregrosa et al., 109 2014).

The secondary variables recorded at the first visit were: gender (male or female), age

111 (years), prescription of antidepressants (yes or no), type of PPI (omeprazole or others), non112 guideline-recommended prescription (NGRP) of PPIs and the total number of drugs. PPIs are

113 indicated mainly in diseases related to gastric acid secretion. They are also used for prevention of 114 secondary drug gastropathies and may also be indicated in more specific pathologies that require 115 short-term treatment (Robinson \& Horn, 2003; Domingues \& Moraes-Filho, 2014;

116 Administración de la Comunidad Autónoma del País Vasco, 2016). All these variables are 117 contained in the electronic prescription, which includes all information relating to drug 118 prescriptions for each patient, along with the age and gender of the patient.

119 Our secondary variables were chosen with the aim of using them to explain the nonadherence. Other studies on adherence to PPIs have shown that sociodemographic factors 121 may influence the correct taking of medication. In addition, we studied NGRP of PPIs, because 122 the presence of gastric symptoms (main recommendation of the guidelines) (Robinson \& Horn, 123 2003; Domingues \& Moraes-Filho, 2014; Administración de la Comunidad Autónoma del País 124 Vasco, 2016) is an important factor associated with adherence (Dal-Paz et al., 2012; Lanas et al., 125 2012). Studies on other drugs have determined that the more prescriptions a patient has, the 126 greater likelihood of treatment nonadherence (Perseguer-Torregrosa et al., 2014). The variable 
127 'prescription of antidepressants' was included in the study because there was a suspicion that a

128 depressed patient could have greater forgetfulness when taking the medication prescribed by his

129 or her physician. Finally, since most prescriptions contained the active ingredient omeprazole,

130 we wanted to determine whether its use was associated with a lower nonadherence.

131 Sample size calculation

132 As the objective of our work was to construct a predictive model (a logistic regression model),

133 the sample size had to be based on the events-per-variable ratio. This ratio had to be greater than

134 10. In our study we had 99 events (patients with nonadherence), therefore with this sample size

135 we could construct a predictive model with 9 explanatory variables (Palazón-Bru et al., 2017).

136 Statistical methods

137 The qualitative variables were described by calculating absolute and relative frequencies

138 (percentages), while quantitative variables were described by calculating the median and

139 interquartile range. Since data from three pharmacies in different locations were used, the

140 homogeneity of the same was verified beforehand through tests based on the $\chi^{2}$ (Pearson or

141 Fisher) and the median tests. After verifying the homogeneity, all data were analyzed together.

142 A binary logistic regression model was constructed in which the dependent variable was

143 therapeutic nonadherence to PPIs and the independent variables were our secondary variables

144 (gender, age, antidepressants, omeprazole, NGRP of PPIs, and the total number of drugs).

145 Through this model, the adjusted relative risks (RR) were obtained. The goodness-of-fit of our

146 model was performed using the likelihood ratio test, Hosmer-Lemeshow test and Nagelkerke's

$147 \mathrm{R}^{2}$. The model was adapted to a points system through the methodology of the Framingham

148 study (Sullivan, Massaro \& D'Agostino, 2004), which weights coefficients determining an

149 associated score for each variable and thus can be used in routine clinical practice. This 
150 methodology has been applied to various areas of knowledge in the field of medicine (Artigao-

151 Ródenas et al., 2015; Azrak et al., 2015; Gutiérrez-Gómez et al., 2015; López-Bru et al., 2015;

152 Palazón-Bru et al., 2015; Ramírez-Prado et al., 2015a). After calculating the score associated

153 with each patient, the ROC curve was calculated and the cut-off point was established as the one

154 that minimized the square root of (1-Sensitivity) ${ }^{2}+(1-\text { Specificity })^{2}$ (Hanley \& McNeil, 1982).

155 After obtaining this point, sensitivity, specificity, positive (PPV) and negative predictive values

156 (NPV) and positive (PLR) and negative likelihood ratios (NLR) were calculated.

157 To perform internal validation of the points system, 1000 bootstrap samples from the

158 original sample were taken (random samples with replacement of the same number of elements

159 as the original sample) (Steyerberg et al., 2001) and in each of them sensitivity, specificity and

160 AUC were calculated. Thus we obtained a distribution for the three parameters, which was

161 represented through histograms.

162 The type I error was set at 5\% for all calculations and for each relevant parameter its 163 associated confidence interval (CI) was calculated. All calculations were implemented with

164 IBMS SPSS Statistics 19 R 2.13.2.

165 Ethical issues

166 The study was approved by the Ethics Committee of the Department of Health of Elda and both

167 data collection and analysis were conducted anonymously and encrypted. All patients gave their 168 consent to participate in the study orally.

169 Mobile Application

170 The points system has been integrated into an application for mobile phones with the Android 171 operating system. Download from the store (Google Play) is free. The name of this application is 172 Nonadherence to PPIs. 


\section{RESULTS}

175 A total of 302 patients were invited to participate during the study period. No patient refused to

176 participate or was lost to follow-up. Our number of recruited patients was higher than the sample

177 size calculated a priori. Of all the patients analyzed, 99 showed nonadherence to PPIs $(32.8 \%$,

$17895 \%$ CI: 27.5-38.1\%). The descriptive characteristics of the sample (Table 1) showed a

179 proportion of men close to half $(45.7 \%), 36.1 \%$ had prescriptions for antidepressants, $63.6 \%$ of

180 the prescriptions were inappropriate, the median age was 70 years and the median number of

181 drugs prescribed was five. There were no differences between the three pharmacies analyzed in 182 any of the variables, with p-values ranging between 0.153 and 0.972 (Table 1).

183 Table 2 shows the estimated RR through the multivariate model, which had a very 184 satisfactory goodness-of-fit in all the tests used (likelihood ratio test, $\mathrm{p}<0.001$; Hosmer185 Lemeshow test, $\mathrm{p}=0.181$; Nagelkerke's $\mathrm{R}^{2}, 0.483$ ). After adapting to a points system (Fig. 2), 186 three variables remained in the system (total number of drugs, NGRP of PPIs, and antidepressants). Applying the scores in our patients gave an AUC near 90\% (Fig. 3) and the 188 optimal point had a value of four, that is, if the patient had a total score greater than or equal to 4 points, the test was considered to be positive. The test parameters were: sensitivity, 0.80 (95\% CI: 0.70-0.87); specificity 0.82, (95\% CI: 0.76-0.87); PPV, 0.69 (95\% CI: 0.59-0.77); NPV, 0.89 (95\% CI: 0.84-0.93); PLR, 4.50 (95\% CI: 3.29-6.15); and NLR, 0.25 (95\% CI: 0.17-0.37). and the sensitivity and specificity above 0.75 . 


\section{DISCUSSION}

197 Summary

198 This study constructed and internally validated a points system to predict therapeutic

199 nonadherence to PPIs. This system showed a very satisfactory goodness-of-fit both in the

200 construction and validation. In addition, to facilitate its use by health professionals, this system

201 has been implemented in a mobile application for the Android operating system.

202 Strengths and limitations of the study

203 The main strength of our work is the clinical idea developed as, in an innovative way, we 204 constructed and internally validated a prediction model to attempt to reduce nonadherence to 205 PPIs and consequently the risk of gastrointestinal problems (Jonasson et al., 2013; Domingues \& 206 Moraes-Filho, 2014). Second, we corroborated the validation with 1000 samples and in all of 207 them we obtained very high sensitivity, specificity and AUC values, giving greater validity to 208 our results. Finally, using a mobile phone application in the world of technology could help 209 implement our prediction model in clinical practice, because in just a few seconds the doctor can know if the patient is at risk of nonadherence to PPI medication. and there were no differences in the three pharmacies analyzed. Information bias was minimized, as our source of information (electronic prescriptions) collects all information used in our study accurately and nonadherence was assessed with a direct method (Perseguer-Torregrosa et al., 2014). Confounding bias was minimized through the use of a multivariate logistic regression model. Also, nonsignificant variables remained in the points system. We must keep in mind that we were assessing the comprehensiveness of the model when making the prediction and not each variable separately (Ramírez-Prado et al., 2015b; Palazón-Bru et al., 2016; Piqueras-Rodríguez 
219 et al., 2016). On the other hand, variables that others have shown to be associated with poorer

220 PPI adherence were not included (Dal-Paz et al., 2012; Lanas et al., 2012). However, without the

221 use of these factors we obtained a very satisfactory discriminating capacity (AUC $=0.87$ ). For

222 example, if we had included the length of time of prescribed treatment it is likely that our AUC

223 would have improved. Nonetheless, a value close to $90 \%$ is an indicator of high discrimination

224 between the nonadherent and the adherent patient. Finally, as a methodological limitation, using

225 a mobile application may have the disadvantage that some people may not be familiar with new

226 technologies. However, these people could still apply the scoring system manually.

\section{Comparison with the existing literature}

228 If we compare our points system with the direct and indirect methods for evaluating therapeutic

229 nonadherence, we see that our system contains only objective variables, assessment is made in a

230 matter of seconds (mobile application) and the estimation error is low. Direct methods (pill count

231 and days covered) are complex to carry out owing to the need to verify whether the patient is

232 taking the medication by checking the PPI container, which presents serious difficulties in

233 routine clinical practice, since we cannot have the patient come in for an appointment only to see

234 if he or she is taking the prescribed medication. On the other hand, the indirect methods require a

235 good doctor-patient relationship and they are not as accurate as direct methods (Perseguer-

236 Torregrosa et al., 2014). In other words, we have created an indirect method to assess

237 nonadherence based on completely objective variables and that does not require a close doctor-

238 patient relationship, because simply by looking at the prescription made by the doctor, we will be

239 able to apply the prediction model.

Regarding the prevalence of nonadherence and its associated factors, our results were consistent with those found by others (Dal-Paz et al., 2012; Lanas et al., 2012; Hedberg et al., 
242 2013; Jonasson et al., 2013; Domingues \& Moraes-Filho, 2014; Henriksson, From \& Stratelis,

243 2014), with the exception of antidepressant treatment, which was not assessed by others. We

244 believe that this could be because a depressed person forgets to take medication. However, as

245 other authors have suggested (Martínez-St John et al., 2015; Rico-Ferreira et al., 2015), this

246 hypothesis should be analyzed through a qualitative study with this type of patient to determine

247 the causes of PPI nonadherence.

248 Implications to research and practice

249 External validation in other geographical areas in which the discriminatory capacity of the

250 constructed test (AUC) is determined, as well as the sensitivity and specificity, is proposed. If the

251 results obtained are similar to those of our study, we will have a screening test to detect which

252 patient is not adhering to the PPI treatment and empathetically try to explain the consequences of

253 nonadherence (Dal-Paz et al., 2012; Jonasson et al., 2013; Domingues \& Moraes-Filho, 2014).

254 Finally, it would be interesting to replicate this study with a longer follow-up time.

255 As the screening test contains objective parameters that can be obtained through the

256 electronic prescription it is possible to determine at the pharmacy which patients are most at risk

257 of PPI nonadherence and thus improve the relationship between the pharmacies and doctors, all

258 to the benefit of the patient.

\section{CONCLUSIONS}

261 A points system to predict nonadherence to PPIs has been constructed and internally validated.

262 The system has been implemented in an application for Android. External validation of our

263 prediction model in other geographical areas is planned. If similar results are obtained, we will 
264 have a screening tool to detect nonadherence and thus reduce possible gastrointestinal

265 complications.

266

267 ACKNOWLEDGMENTS

268 The authors thank Maria Repice and Ian Johnstone for their help with the English language

269 version of the text. 
270

271

272

273

274

275

276

277

278

279

280

281

282

283

284

285

286

287

288

289

290

291

\section{REFERENCES}

Administración de la Comunidad Autónoma del País Vasco (Departamento de Salud). 2016.

Inhibidores de la Bomba de Protones: Recomendaciones de Uso. Donostia-San Sebastián, Spain:

Servicio Central de Publicaciones del Gobierno Vasco.

Artigao-Ródenas LM, Carbayo-Herencia JA, Palazón-Bru A, Divisón-Garrote JA, Sanchis-

Domènech C, Vigo-Aguiar I, Gil-Guillén VF. 2015. Construction and Validation of a 14-Year

Cardiovascular Risk Score for Use in the General Population: The Puras-GEVA Chart. Medicine (Baltimore) 94: e1980.

Azrak C, Palazón-Bru A, Baeza-Díaz MV, Folgado-De la Rosa DM, Hernández-Martínez C, Martínez-Toldos JJ, Gil-Guillén VF. 2015. A predictive screening tool to detect diabetic retinopathy or macular edema in primary health care: construction, validation and implementation on a mobile application. PeerJ 3: e1404.

Dal-Paz K, Moraes-Filho JP, Navarro-Rodriguez T, Eisig JN, Barbuti R, Quigley EM. 2012. Low levels of adherence with proton pump inhibitor therapy contribute to therapeutic failure in gastroesophageal reflux disease. Diseases of the Esophagus 25: 107-113.

Domingues G, Moraes-Filho JP. 2014. Noncompliance is an impact factor in the treatment of gastroesophageal reflux disease. Expert Review of Gastroenterology \& Hepatology 8:761-765. 
292 Fass R, Shapiro M, Dekel R, Sewell J. 2005. Systematic review: proton-pump inhibitor failure in

293 gastro-oesophageal reflux disease--where next? Alimentary Pharmacology \& Therapeutics 22:

294 79-94. Review.

295

296 Foro de Atención Farmacéutica. 2008. Documento de Consenso. Madrid, Spain: Consejo

297 General de Colegios Oficiales de Farmacéuticos.

298

Gutiérrez-Gómez T, Cortés E, Palazón-Bru A, Peñarrieta-de Córdova I, Gil-Guillén VF, Ferrer-

Diego RM. 2015. Six simple questions to detect malnutrition or malnutrition risk in elderly women. PeerJ 3: e1316.

302

Hanley JA, McNeil BJ. 1982. The meaning and use of the area under a receiver operating characteristic (ROC) curve. Radiology 143:29-36.

305

Hedberg J, Sundström J, Thuresson M, Aarskog P, Oldgren J, Bodegard J. 2013. Low-dose acetylsalicylic acid and gastrointestinal ulcers or bleeding--a cohort study of the effects of proton pump inhibitor use patterns. Journal of Internal Medicine 274: 371-380.

Henriksson K, From J, Stratelis G. 2014. Patient-reported adherence to coprescribed proton pump inhibitor gastroprotection in osteoarthritis, rheumatoid arthritis, and ankylosing spondylitis 1617. 
315 Hungin AP, Rubin G, O'Flanagan H. 1999. Factors influencing compliance in long-term proton

316 pump inhibitor therapy in general practice. British Journal of General Practice 49: 463-464.

318 Jonasson C, Hatlebakk JG, Lundell L, Kouri JP, Andersen M, Granath F. 2013. Association

319 between adherence to concomitant proton pump inhibitor therapy in current NSAID users and

320 upper gastrointestinal complications. European Journal of Gastroenterology \& Hepatology 25:

$321 \quad 531-538$.

322

323

Lanas A, Polo-Tomás M, Roncales P, Gonzalez MA, Zapardiel J. 2012. Prescription of and

adherence to non-steroidal anti-inflammatory drugs and gastroprotective agents in at-risk gastrointestinal patients. American Journal of Gastroenterology 107: 707-714.

326

López-Bru D, Palazón-Bru A, Folgado-de la Rosa DM, Gil-Guillén VF. 2015. Scoring System 328 for Mortality in Patients Diagnosed with and Treated Surgically for Differentiated Thyroid Carcinoma with a 20-Year Follow-Up. PLoS One 10: e0128620.

Martínez-St John DR, Palazón-Bru A, Gil-Guillén VF, Sepehri A, Navarro-Cremades F,

Diagnostic inertia in obesity and the impact on cardiovascular risk in primary care: a crosssectional study. British Journal of General Practice 65: e454-459.

Palazón-Bru A, Martínez-Orozco MJ, Perseguer-Torregrosa Z, Sepehri A, Folgado-de la Rosa 
338 validation of a model to predict nonadherence to guidelines for prescribing antiplatelet therapy to

339 hypertensive patients. Current Medical Research and Opinion 31: 883-889.

341 Palazón-Bru A, Carbayo-Herencia JA, Vigo MI, Gil-Guillén VF. 2016. A method to construct a 342 points system to predict cardiovascular disease considering repeated measures of risk factors.

343 PeerJ 4: e1673.

344

Palazón-Bru A, Folgado-de la Rosa DM, Cortés-Castell E, López-Cascales MT, Gil-Guillén VF. 346 2017. Sample size calculation to externally validate scoring systems based on logistic regression

347

348

349

350

351

352

353

354

355

356

357

358

359

360

Perseguer-Torregrosa Z, Orozco-Beltrán D, Gil-Guillen VF, Pita-Fernandez S, CarrataláMunuera C, Pallares-Carratalá V, Lopez-Pineda A. 2014. Magnitude of pharmacological nonadherence in hypertensive patients taking antihypertensive medication from a community pharmacy in Spain. Journal of Managed Care \& Specialty Pharmacy 20: 1217-1225.

Piqueras-Rodríguez F, Palazón-Bru A, Martínez-St John DR, Folgado-de la Rosa DM, GilGuillén VF. 2016. A Tool to Quickly Detect Short Hamstring Syndrome in Boys who Play Soccer. International Journal of Sports Medicine 37: 1-5.

Ramírez-Prado D, Palazón-Bru A, Folgado-de la Rosa DM, Carbonell-Torregrosa MÁ, Martínez-Díaz AM, Martínez-St John DR, Gil-Guillén VF. 2015. A four-year cardiovascular risk score for type 2 diabetic inpatients. PeerJ 3: e984. 
362 Ramírez-Prado D, Palazón-Bru A, Folgado-de-la Rosa DM, Carbonell-Torregrosa MÁ, 363 Martínez-Díaz AM, Gil-Guillén VF. 2015. Predictive models for all-cause and cardiovascular 364 mortality in type 2 diabetic inpatients. A cohort study. International Journal of Clinical Practice 365 69: 474-484.

366

367 Rico-Ferreira P, Palazón-Bru A, Calvo-Pérez M, Gil-Guillén VF. 2015. Nonadherence to 368 guidelines for prescribing antibiotic therapy to patients with tonsillitis or pharyngotonsillitis: a 369 cross-sectional study. Current Medical Research and Opinion 31: 1319-1322.

Robinson M, Horn J. 2003. Clinical pharmacology of proton pump inhibitors: what the practising physician needs to know. Drugs 63: 2739-2754.

374 Steyerberg EW, Harrell FE Jr, Borsboom GJ, Eijkemans MJ, Vergouwe Y, Habbema JD. 2001. Internal validation of predictive models: efficiency of some procedures for logistic regression analysis. Journal of Clinical Epidemiology 54: 774-781.

Sturkenboom MC, Burke TA, Tangelder MJ, Dieleman JP, Walton S, Goldstein JL. 2003. anti-inflammatory drugs. Alimentary Pharmacology \& Therapeutics 18: 1137-1147. 
382 Sullivan LM, Massaro JM, D'Agostino RB Sr. 2004. Presentation of multivariate data for clinical 383 use: The Framingham Study risk score functions. Statistics and Medicine 23: 1631-1660.

384 Review.

385

386 van Soest EM, Sturkenboom MC, Dieleman JP, Verhamme KM, Siersema PD, Kuipers EJ.

387 2007. Adherence to gastroprotection and the risk of NSAID-related upper gastrointestinal ulcers

388 and haemorrhage. Alimentary Pharmacology \& Therapeutics 26: 265-275. 
Figure 1

Phases of our study design. 


\section{Month of follow-up}

First visit

(beginning of the prescription)

Inclusion and

exclusion criteria

\section{Second visit}

(halfway through the prescription)

Pill counts

Third visit

(completion of the prescription)

\section{Pill counts}


Figure 2

Scoring system to predict nonadherence to proton pump inhibitors.

Abbreviations: PPI, proton pump inhibitors; NGRP, non-guideline-recommended prescription.

Guideline-recommended-prescription of PPI: prevention of upper gastrointestinal disorders in high-risk patients (Robinson \& Horn, 2003; Domingues \& Moraes-Filho, 2014; Administración de la Comunidad Autónoma del País Vasco, 2016).

\section{Total number of drugs Score}

\section{NGRP of PPI Score}

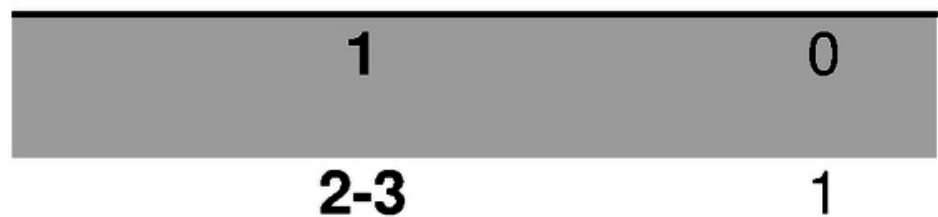

2
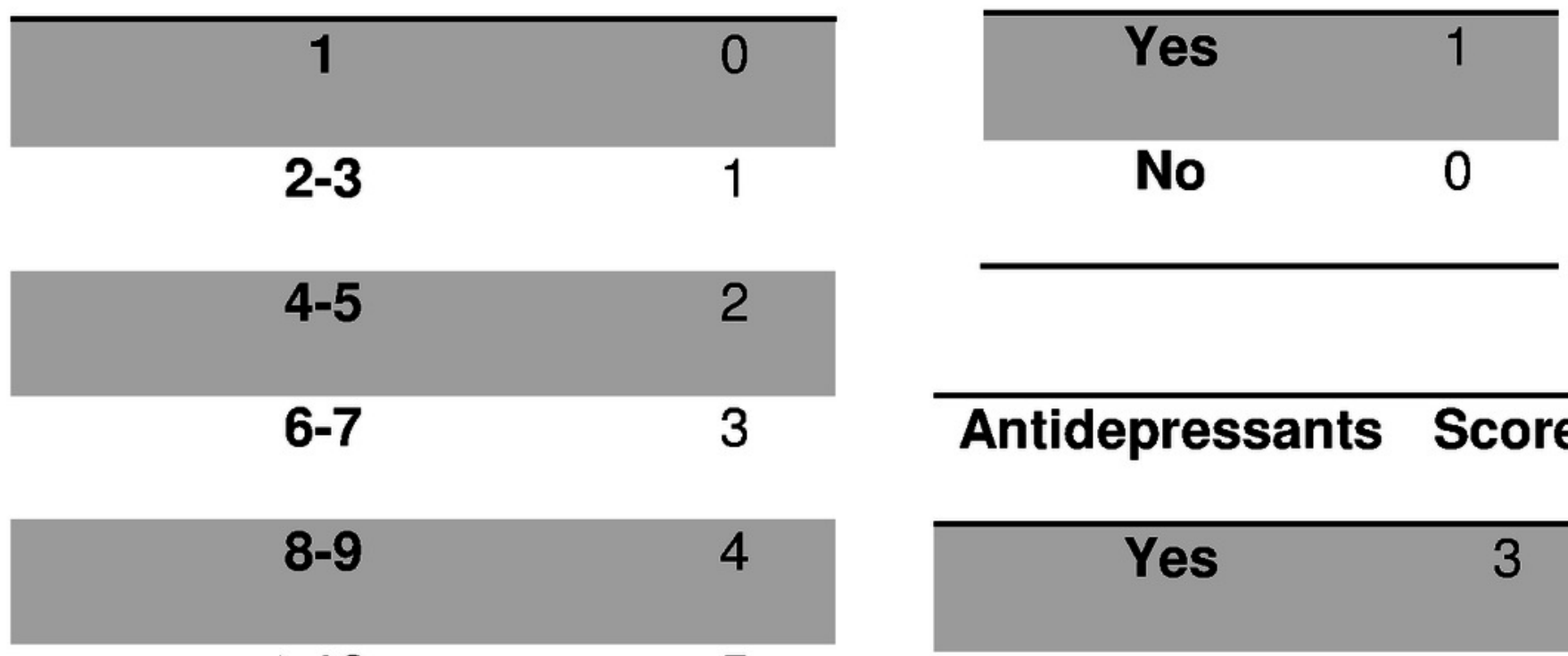

No

0

$\geq 10$

5

Antidepressants Score

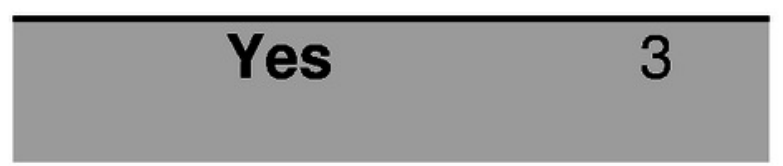

No

0

\section{Total score Outcome}

\begin{tabular}{ll}
\hline $\mathbf{2}$ & Positive \\
$<4$ & Negative \\
\hline
\end{tabular}


Figure 3

Area under the ROC curve for the scoring system to predict nonadherence to proton pump inhibitors.

Abbreviations: AUC, area under the ROC curve; $\mathrm{Cl}$, confidence interval.

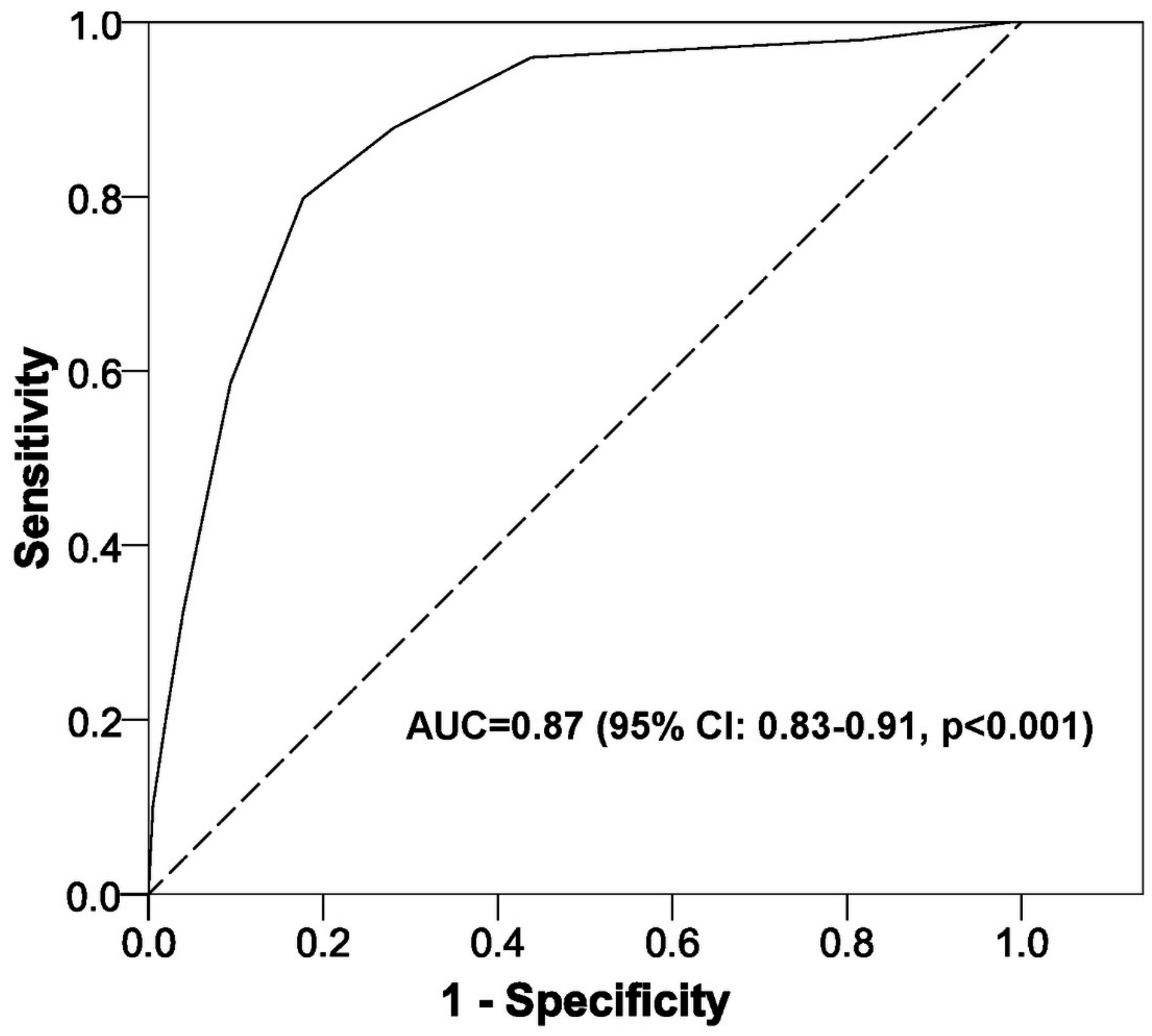




\section{Figure 4}

Internal validation of the scoring system to predict nonadherence to proton pump inhibitors.

A, area under the ROC curve; $B$, sensitivity; $C$, specificity. Abbreviations: AUC, area under the ROC curve. 

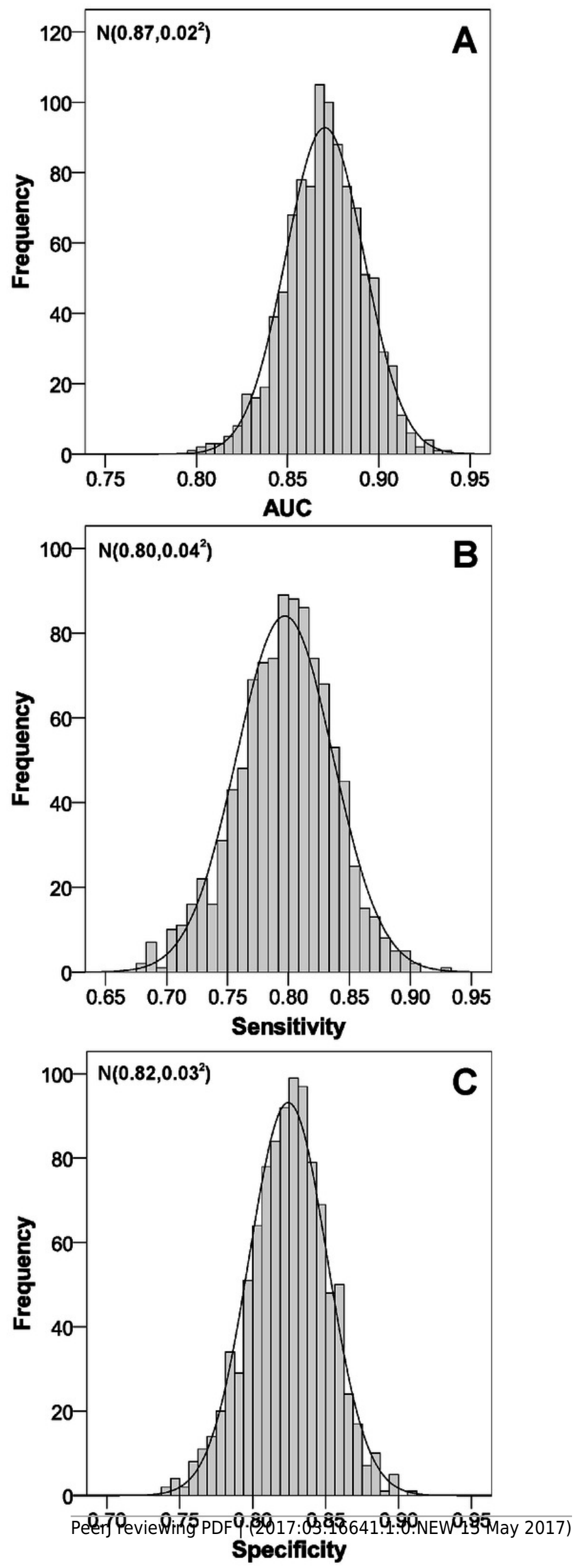


\section{Table $\mathbf{1}$ (on next page)}

Descriptive analysis of the patients between the three participant pharmacies (Elda, Santa Pola and San Vicente del Raspeig).

Abbreviations: IQR, interquartile range; NGRP, non-guideline-recommended prescription; $\mathrm{n}(\%)$, absolute frequency (relative frequency); PPI, proton pump inhibitors. Guidelinerecommended prescription of $\mathrm{PPI}$ : prevention of upper gastrointestinal disorders in high-risk patients (Robinson \& Horn, 2003; Domingues \& Moraes-Filho, 2014; Administración de la Comunidad Autónoma del País Vasco, 2016). 


\begin{tabular}{|l|c|c|c|c|c|}
\hline \multirow{2}{*}{ Variable } & $\begin{array}{c}\text { Total } \\
\mathrm{n}=302 \\
\mathrm{n}(\%) / \text { median(IQR) }\end{array}$ & $\begin{array}{c}\text { Pharmacy 1 } \\
\mathrm{n}=183 \\
\mathrm{n}(\%) / \text { median(IQR) }\end{array}$ & $\begin{array}{c}\text { Pharmacy 2 } \\
\mathrm{n}=74 \\
\mathrm{n}(\%) / \text { median(IQR) }\end{array}$ & $\begin{array}{c}\text { Pharmacy } 3 \\
\mathrm{n}(\%) / \text { median(IQR) }\end{array}$ & $\begin{array}{c}\mathrm{p}- \\
\text { value }\end{array}$ \\
\hline Nonadherence to PPI & $99(32.8)$ & $59(32.2)$ & $28(37.8)$ & $12(26.7)$ & 0.439 \\
\hline Male gender & $138(45.7)$ & $87(47.5)$ & $33(44.6)$ & $18(40.0)$ & 0.645 \\
\hline Antidepressants & $109(36.1)$ & $67(36.6)$ & $26(35.1)$ & $16(35.6)$ & 0.972 \\
\hline Omeprazole & $234(77.5)$ & $144(78.7)$ & $60(81.1)$ & $30(66.7)$ & 0.156 \\
\hline NGRP of PPI & $192(63.6)$ & $116(63.4)$ & $48(64.9)$ & $28(62.2)$ & 0.955 \\
\hline Age (years) & $70(20)$ & $70(20)$ & $67(21)$ & $72(16)$ & 0.700 \\
\hline Total number of drugs & $5(4)$ & $5(4)$ & $6(4)$ & $4(3)$ & 0.153 \\
\hline
\end{tabular}




\section{Table 2 (on next page)}

Multivariate analysis of nonadherence to proton pump inhibitor drugs.

Abbreviations: Adj. RR, adjusted relative risk; $\mathrm{Cl}$, confidence interval; NGRP, non-guidelinerecommended prescription; PPI, proton pump inhibitors. Guideline-recommended prescription of PPI: prevention of upper gastrointestinal disorders in high-risk patients (Robinson \& Horn, 2003; Domingues \& Moraes-Filho, 2014; Administración de la Comunidad Autónoma del País Vasco, 2016). Goodness-of-fit of the model: $X^{2}=128.7, p<0.001$, Hosmer-Lemeshow $X^{2}=7.6$, $p=0.181$ Nagelkerke's $R^{2}=0.483$. 


\begin{tabular}{|l|c|c|}
\hline Variable & $\begin{array}{c}\text { Adj. RR } \\
(95 \% \mathrm{CI})\end{array}$ & $\mathrm{p}$-value \\
\hline Male gender & $1.29(0.66-2.55)$ & 0.456 \\
\hline Antidepressants & $11.91(6.01-23.58)$ & $<0.001$ \\
\hline Omeprazole & $0.87(0.38-1.96)$ & 0.735 \\
\hline NGRP of PPI & $1.75(0.83-3.68)$ & 0.138 \\
\hline Age (years) & $1.00(0.97-1.03)$ & 0.869 \\
\hline Total number of drugs & $1.49(1.28-1.74)$ & $<0.001$ \\
\hline
\end{tabular}

1 